\title{
ATLANTOAXIAL SUBLUXATION IN A PATIENT WITH PSORIATIC ARTHRITIS: A CASE REPORT
}

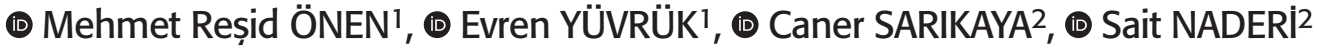 \\ ${ }^{1}$ VM Maltepe Medicalpark Hospital, Clinic of Neurosurgery, Istanbul, Turkey \\ 2 Ümraniye Training and Research Hospital, Clinic of Neurosurgery, İstanbul, Turkey
}

\begin{abstract}
Psoriatic arthritis (PsA) is a chronic inflammatory arthritis associated with psoriasis. While psoriasis is seen in $1-2 \%$ of the general population, PsA is seen in $6-40 \%$ of psoriasis patients. In $70 \%$ of patients with PsA, the cervical spine is affected and myelopathy develops. The case presented is that of a patient with non-traumatic, upper cervical instability on the basis of PsA, who was diagnosed of myelopathy and was treated surgically. Keywords: Psoriasis, psoriatic arthritis, spondyloarthropathy, cervical instability, atlantoaxial subluxation
\end{abstract}

\section{INTRODUCTION}

Spondyloarthropathy $(\mathrm{SpA})$ is a disease group characterised by synovitis and enteritis, with spinal and oligoarticular involvement, for which there is a genetic predisposition. Psoriasis is a rheumatismal disease which manifests with arthritis, negative rheumatoid factor and the presence of HLA-B27 antigen especially in those with spinal involvement. Psoriatic arthritis (PsA) is a chronic inflammatory arthritis associated with psoriasis. It is a member of the SpA family with common immunopathological, clinical and radiological features. Psoriasis is seen in $1-2 \%$ of the general population while PsA in $6-40 \%$ of psoriasis patients ${ }^{(1)}$. Although it may be seen at any age, the frequency increases in the 30-50 years age group (2). In $70 \%$ of patients with PsA, the cervical spine is affected and myelopathy develops in a very small proportion of these patients ${ }^{(3)}$.

The case presented here is that of a patient with non-traumatic, upper cervical instability on the basis of PsA, who was diagnosed of myelopathy and was treated surgically.

\section{CASE REPORT}

A 48-year-old male diagnosed with psoriasis 24 years ago was presented with complaints of neck pain and paraesthesia in the right arm which had been ongoing for 4 months. The patient had no history of trauma and physical examination revealed increase in deep tendon reflexes and the bilateral Hoffmann sign was determined. No motor deficit was observed. According to the laboratory tests, result showed that rheumatoid factor was negative and HLA-B27 was positive. On magnetic resonance imaging, on the $\mathrm{T} 2$ sequence, a hyperintense lesion was seen within the spinal cord at the C1-2 level, which was interpreted as myelomalacia. On the dynamic cervical magnetic resonance (MR) images, an advanced degree of narrowness was determined in the spinal canal at C1-2 and C3-4 levels, especially in extension (Figure $1 \mathrm{~A}$ and $\mathrm{B}$ ). On dynamic computed tomography and plain radiographs, there were evident findings of instability at both levels and the diameter of the spinal canal was reduced (Figure $2 \mathrm{~A}-\mathrm{C}$ ). Widespread ligament calcification was seen and fusion had developed especially between the lower cervical vertebrae.

The patient was positioned prone with the head in a Mayfield headpiece under general anaesthesia. With a midline approach, the muscles were stripped bilaterally from suboccipital as far as C5 level. First, by placing C1 lateral mass screws, C2 pedicular screw and C3, 4 and 5 lateral mass screws, they were joined with a rod. Then C1 laminectomy was applied, C2 sublaminar decompression, and decompression with C3-4 interspinous ligament and ligamentum flavum excision. No perioperative

Address for Correspondence: Mehmet Reşid Önen, VM Maltepe Medicalpark Hospital, Clinic of Neurosurgery, istanbul, Turkey E-mail: mresid@gmail.com Received: 28.08.2020 Accepted: 02.10.2020

ORCID ID: orcid.org/0000-0003-4353-9068 
complications developed. Postoperatively, no motor or sensory deficit was observed in the patient. On MR and X-ray imaging, the spinal cord was seen to have been decompressed (Figures $3 \mathrm{~A}$ and $\mathrm{B}$ ). The patient was followed for about 2 years. Pain complaints of the patient decreased. No walking disorder detected.

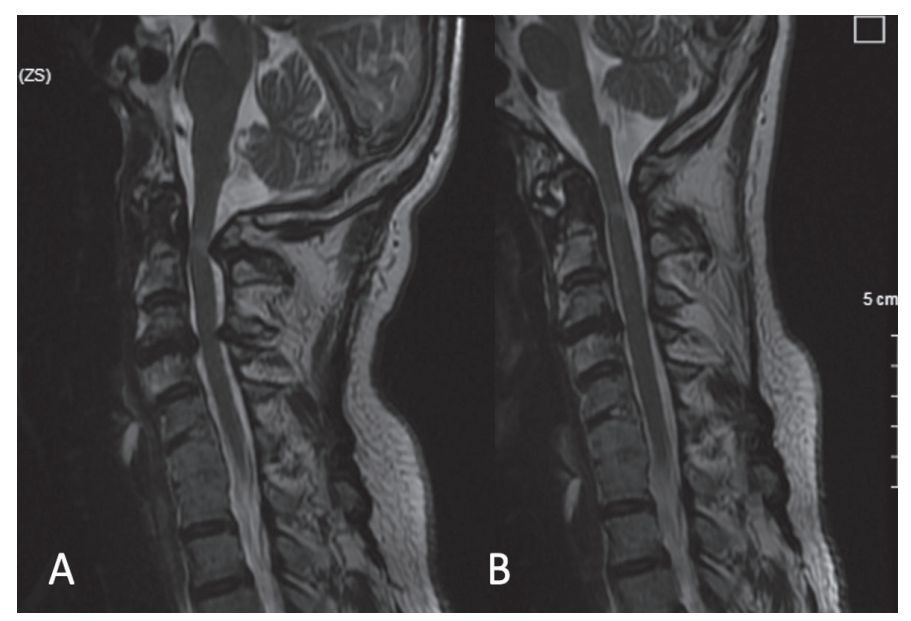

Figure 1. Atlantoaxial subluxation and myelopathy (A) extension, (B) flexion position of the dynamic cervical magnetic resonance images
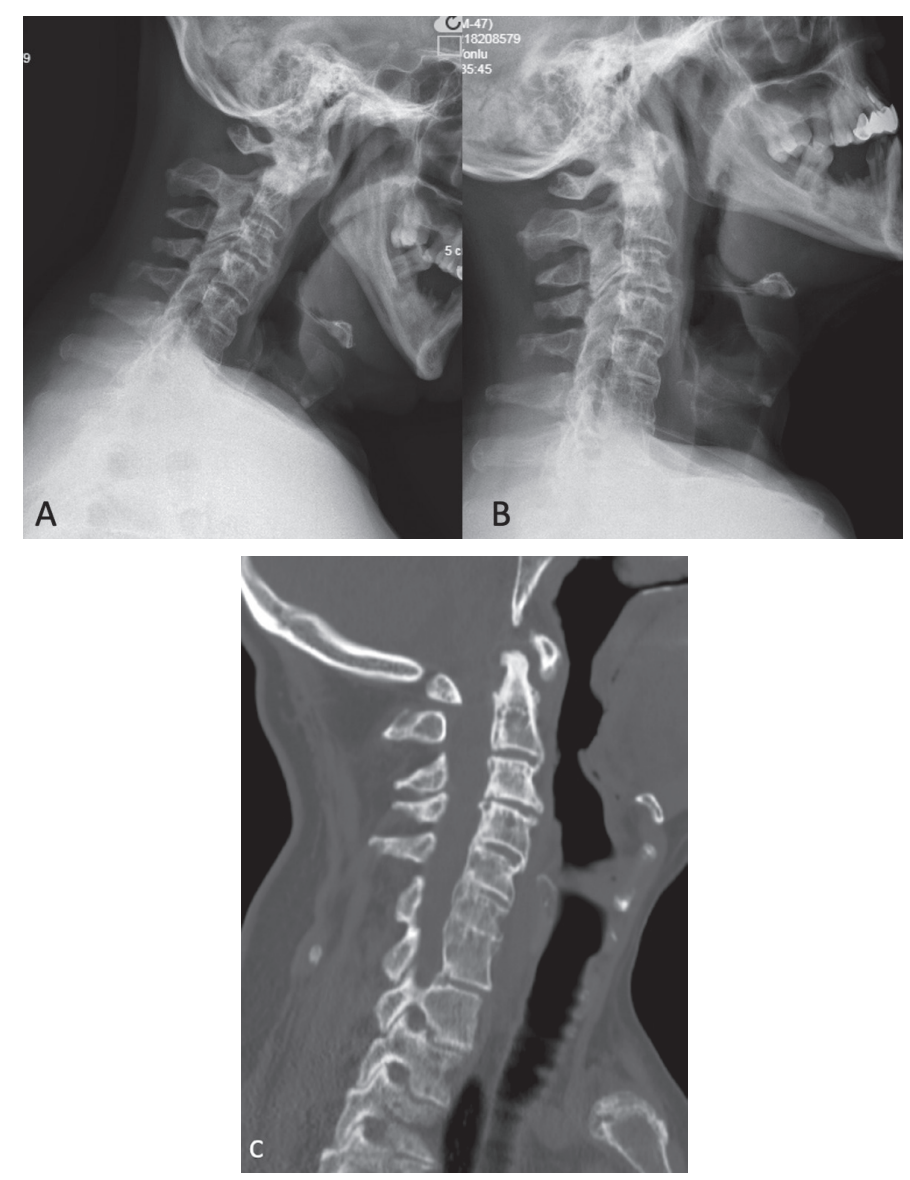

Figure 2. Atlantoaxial subluxation showing dynamic cervical X-ray images (A) flexion, (B) extension, and (C) cervical sagittal computed tomography image

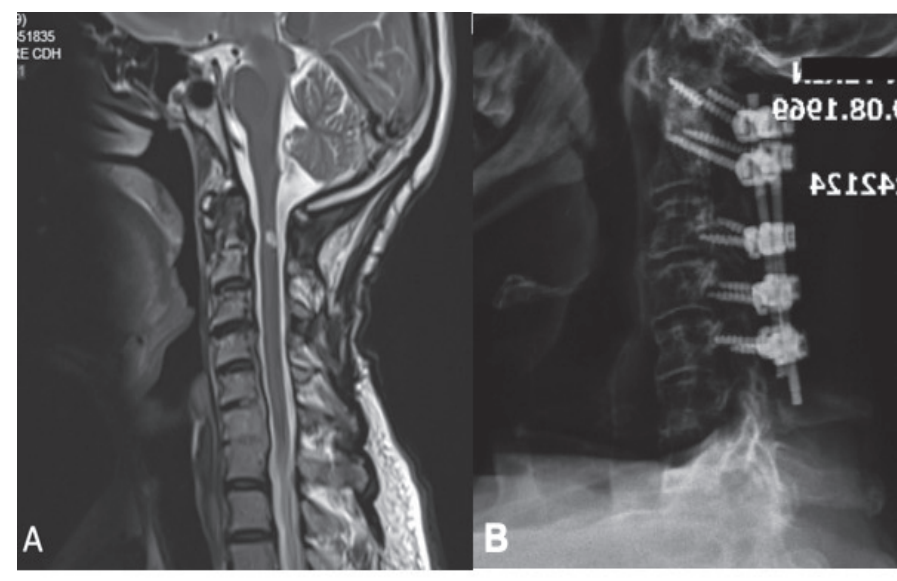

Figure 3. Postoperative cervical spine (A) magnetic resonance sagittal T2 weighted images, and (B) lateral X-ray image. Myelopathy can be seen easily after spinal canal decompression

\section{DISCUSSION}

Psoriatic arthritis (PsA) is classified as inflammatory arthritis associated with psoriasis, which progresses to joint destruction ${ }^{(4)}$. The exact prevalence of PsA is not known taking into consideration there is no globally accepted criteria. The prevalence in patients with psoriasis varies between 6\% and $42 \%$, and in $17 \%$ of cases, there are no skin findings ${ }^{(2)}$. Although the cause of the disease is not fully known, genetic, immunological and environmental factors are thought to play a role in the pathogenesis. There is no specific laboratory test for PsA. Non-steriods, disease-modifying drugs, corticosteroids and biological agents are used in treatment ${ }^{(1,5)}$.

Axial spine involvement can generally be seen in $20-40 \%$ of PsA cases, and this rate can increase up to $51 \%$ in long-term follow-up ${ }^{(5,6)}$. As the duration of the disease and the number of peripheral joints involved increase, the percentage of cervical spine involvement increases also ${ }^{(5)}$. There may be sacroiliac involvement at a 30-50\% rate, symmetrically or asymmetrically ${ }^{(7,8)}$. Radiological cervical spine findings are relatively common (35-75\%) in PsA patients ${ }^{(3)}$. Cervical spine lesions have been reported as apophyseal joint erosion, vertebral plate erosion and atlantoaxial subluxation ${ }^{(3)}$. Cervical spine anomalies are seen in two patterns in PsA. The first pattern is a table of erosive and/or cervical subluxation as in rheumatoid arthritis, and the second pattern is ligament ossification and ankylosis resembling ankylosing spondylitis(9). In these patients, odontoid erosion may develop at a low incidence. Neurological complication rates are low despite cervical involvement in PsA $(2-14 \%)^{(3,9,10)}$.

Symptoms in cervical spine pathologies which develop associated with degenerative or inflammatory etiologies are axial neck pain, myelopathy or radiculopathy. Neck pain is the most frequently seen finding associated with cervical region involvement in SpA. Myelopathy develops associated with brainstem or spinal cord pressure. Early findings associated with 
myelopathy are difficulty in walking or maintaining balance and in the later stage, motor neuron findings are seen ${ }^{(11)}$.

Surgical treatment is applied to patients with findings of instability and/or myelopathy and to cases which develop, radiculopathy. It is important that instability is treated before the emergence of myelopathy findings in particular. In 43-70\% of patients diagnosed of cervical instability because of PsA, neurological deficits develop within 5 years ${ }^{(12)}$.

Several different methods are used in the fusion of C1-C2 vertebrae in the surgical treatment of atlantoaxial instability. It is necessary to add the occipital bone to C1-C2 fusion if there is accompanying basilar invagination. Generally, when there is stenosis of the spinal cord or nerve roots, spinal cord decompression is applied. Autogenous bone grafts are preferred for fusion purposes. The current, most widely used surgical method is the application of decompression by placing mass screws to $C 1$ and pedicle screws to $C 2$ if necessary ${ }^{(13)}$.

In the case presented, as there was no accompanying basilar invagination, occipital screws were not applied. Spinal stenosis was determined related to posterior ligament thickening in the C2-C3 space in addition to stenosis and C1-C2 instability, therefore, $\mathrm{C} 1$ mass, $\mathrm{C} 2$ pedicle and C3-4-5 lateral mass screws were applied. C1 laminectomy was applied for decompression, C2 sublaminar decompression, and C3-4 space decompression was achieved with ligamentum flavum excision. Autogenic bone was used for fusion (Figures $3 A$ and B).

In conclusion, it must be taken into consideration that a narrow spinal canal and instability could develop in PsA, and in cases with the risk of cervical instability in particular, the application of surgical treatment before myelopathy findings emerge will significantly prevent morbidity.

\section{Ethics}

Informed Consent: Informed consent was obtained from the patient regarding that their surgery and the surgical approvement would be published as a case presentation article of ours entitled "Atlantoaxial Subluxation in a Patient with Psoriatic Arthritis: a case report".

Peer-review: Externally peer-reviewed.

\section{Authorship Contributions}

Surgical and Medical Practices: M.R.Ö., E.Y., C.S., S.N., Concept: C.S., Design: M.R.Ö., E.Y., Data Collection or
Processing: C.S., Analysis or Interpretation: M.R.Ö., S.N., Literature Search: C.S., Writing: M.R.Ö.

Conflict of Interest: No conflict of interest was declared by the authors.

Financial Disclosure: The authors declared that this study did not receive any financial support.

\section{REFERENCES}

1. Reiter MF, Boden SD. Inflammatory disorders of the cervical spine. Spine (Phila Pa 1976). 1998;23:2755-66.

2. Gottlieb A, Korman NJ, Gordon KB, Feldman SR, Lebwohl M, Koo IY, et al. Guidelines of care for the management of psoriasis and psoriatic arthritis: Section 2. Psoriatic arthritis: overview and guidelines of care for treatment with an emphasis on the biologics. J Am Acad Dermatol. 2008;58:851-64.

3. Salvarani C, Macchioni P, Cremonesi T, Mantovani W, Battistel B, Rossi $F$, et al. The cervical spine in patients with psoriatic arthritis: a clinical, radiological and immunogenetic study. Ann Rheum Dis. 1992;51:73-7.

4. Wright V, Moll JM. Psoriatic arthritis. In: Wright V, Moll JM (Eds.). Seronegative polyarthritis. Amsterdam: North Holland Publishing CO 1976.pp:169-235.

5. Bruce IN. Psoriatic Arthritis: Clinical Features. In: Hochberg MC, Silman AJ, Smolen JS, Weinblat ME, Weisman MH (Eds.). Rheumatology. 4th ed. Philadelphia: Elsevier Limited 2008.pp.1165-76.

6. Veale $D$, Rogers $S$, Fitzgerald $O$. Classification of clinical subsets in psoriatic arthritis. Br J Rheumatol. 1994;33:133-8.

7. Battistone MJ, Manaster B], Reda DJ, Clegg DO. The prevalence of sacroiliitis in psoriatic artritis: new perspectives from a large, multicenter cohort. A Department of Veterans Affairs Cooperative Study. Skeletal Radiol. 1999:28:196-201.

8. Torre JC, Rodriguez PA, Arribas JM, Ballina GJ, Riestra JL, Lopez LC. Psoriatic arthritis (PA): a clinical, immunological and radiological study of 180 patients. Br J Rheumatol. 1991;30:245-50.

9. Blau RH, Kaufman RL. Erosive and subluxing cervical spine disease in patients with psoriatic arthritis. J Rheumonatol. 1987;14:111-7.

10. Suarez-Almazor ME, Russell AS. Anterior atlantoaxial subluxation in patients with spondyloarthropathies: association with peripheral disease. J Rheumatol. 1988;15:973-5.

11. Kaplan D, Plotz CM, Nathanson L, Frank L. Cervical spine in psoriasis and in psoriatic arthritis. Annals of the rheumatic diseases. 1964;23:50-56.

12. Pellicci PM, Ranawat CS, Tsairis P, Bryan WJ. A prospective study of the progression of rheumatoid arthritis of the cervical spine. JBJS. 1981;63:342-50.

13. Harms J, Melcher RP. Posterior C1-C2 fusion with polyaxial screw and rod fixation. Spine (Phila Pa 1976). 2001;26:2467-71. 